\title{
FEMINISMO, CRÍTICA Y REIVINDICACIÓN EN LA NOVELA SOCIAL DE \\ CARMEN DE BURGOS: LA MALCASADA
}

\section{MÁXIMO CASTAÑO-PENALVA \\ UNIVERSIDAD DE MURCIA}

RESUMEN: La denuncia sobre la inferioridad social y legal de la mujer casada afloró con vigor en los postreros años del siglo XIX y albores del siglo XX en Europa. La polifacética Carmen de Burgos aspiró a crear en la opinión pública española una transformación que modificase esta situación. Para ello se valió, entre otros medios, de la literatura. En su novela La malcasada apreciamos esos anhelos de libertad y progresismo que descubren la marginación femenina; lo inicuo de la indisolubilidad conyugal y una aplicación judicial alejada de la equidad entre géneros.

PALABRAS CLAVE: Divorcio; libertad sentimental; honra; adulterio; derecho de familia.

\section{FEMINISM, CRITICISM AND CLAIM IN THE SOCIAL NOVEL OF CARMEN DE BURGOS: LA MALCASADA}

\begin{abstract}
The denunciation of the social and legal inferiority of the married woman emerged with vigour in the last years of the XIX century and the dawn of the XX century in Europe. The multifaceted Carmen de Burgos aspired to create in the Spanish public opinion a transformation that would modify this situation. For it was worth, among other means, of the literature. In her novel La malcasada we appreciate those yearnings for freedom and progressivism that discover female marginalization; the iniquitous of conjugal indissolubility and a judicial application distanced from gender equity.
\end{abstract}

KEYWORDS: Divorce; sentimental freedom; honour; adultery; family law. 


\section{Introducción}

Pocas mujeres a comienzos del siglo XX desarrollaron una labor tan constante en defensa de los derechos femeninos en España como Carmen de Burgos Segui. La crítica a la sociedad del momento que situaba a la mujer en una flagrante inferioridad, su defensa a ultranza a favor del derecho al divorcio y a la igualdad en el matrimonio entre cónyuges, le propició enormes críticas en los sectores conservadores. No obviemos que la legislación matrimonial en los inicios del pasado siglo recogía un marcado espíritu patriarcal y católico. La regulación de la familia mantenía un espíritu canónico que impedía la ruptura conyugal siguiendo las directrices vaticanas.

El presente artículo aborda la represión y marginación de la mujer en la familia, y singularmente en el matrimonio, desde la perspectiva de la obra literaria de la Carmen de Burgos que empleó esta herramienta para reivindicar el divorcio y mostrar la situación de la mujer. Recordemos que la ruptura del vínculo conyugal no se permitió en España hasta 1932, y perduró hasta el fin de la $\mathrm{II}^{\mathrm{a}}$ República. Antes, la única posibilidad ante las crisis matrimoniales era la separación, que, si bien ponía fin a la vida en común de los esposos, no quebraba el vínculo, imposibilitando nuevas nupcias.

Se aspira a sintetizar un estudio histórico-social e histórico-jurídico que permita analizar, de forma rigurosa, la situación de la mujer casada a comienzos del siglo XX. Merced a la relación entre Historia, Literatura y Derecho se descubre una visión rica e innovadora de nuestro pasado. El valor histórico de la literatura resulta incuestionable, como afirma Enriqueta Vilar, el historiador busca en la literatura un testimonio vivo de una sociedad, de sus creencias y de su mentalidad ${ }^{1}$. José-Carlos Mainer enriquece la idea al afirmar que la literatura, como fuente histórica, nos adentra no en lo acontecido, sino en lo posible o verosímil ${ }^{2}$.

De igual modo, el análisis jurídico nos introduce en la configuración ideológica de una sociedad determinada. Como bien sostiene Cecilia P. Grosman "El derecho de familia implica un conjunto de representaciones respecto de lo que se concibe como un bien para el grupo social”’3.

\footnotetext{
1 VILA VILAR, Enriqueta: "La literatura como fuente histórica: un largo debate para un caso práctico", Boletín de la Real academia Sevillana de Buenas Letras: Minervae Baeticae, № 37 (2009), pp. 9-28.

2 MAINER, José Carlos: "Literatura como historia, historia como literatura", Revista de pensamiento contemporáneo, $\mathrm{N}^{\mathrm{o}} .26$ (2008) pp. 83-92.

${ }^{3}$ GROSMAN, Cecilia P.: El proceso de divorcio. Derecho y realidad. Editorial Abaco de Rodolfo Despalma. Buenos Aires, 1985, p.21.
} 
Historiadoras como Ana Aguado, Geraldine Scanlon, Mary Nash, Concha Fagoaga, Concepción Núñez Rey, y filólogas como Helena Estabelier y Elisa Martínez Garrido han realizado formidables estudios sobre la génesis del movimiento feminista, la situación de la mujer, el divorcio a comienzos del siglo XX y la literatura y biografía de Carmen de Burgos.

El estudio profundo de la solicitud del divorcio, compaginado con la indagación de la situación de la mujer, en la obra novelística de Carmen de Burgos, brinda un fiel reflejo de la sociedad de principios del siglo XX y de las relaciones conyugales. También revela el anhelo inquebrantable de la escritora en su lucha por la libertad sentimental. Para ello, denuncia roles sociales de su época en torno a la familia, al matrimonio, a la regulación normativa y su aplicación judicial. La obra objeto de estudio merece ser incluida en las denominadas novelas sociales, si entendemos por tal género, aquellas que describen, con propósito crítico y de enmienda, injusticia, desigualdad o anquilosamiento de una sociedad ${ }^{4}$.

Recordemos que el Código civil de 1889 regulaba los derechos privados de la mujer. En síntesis, el texto legal la situaba, hasta su reforma en el año 1975, en una minoría de edad, especialmente de la casada. Establecía que la esposa debía obedecer al marido y éste protegerla; disponía el deber de la mujer a fijar su domicilio según fuera el de su marido, esta decisión era obligatoria incluso manu militari; la administración de los bienes de la mujer recaía en su esposo, presuponiendo su inferioridad intelectual; necesitaba el beneplácito marital para realizar operaciones de compra-venta, hipotecas, donaciones, etc., incluso de sus bienes privativos. El Código exceptuaba, exclusivamente, la aquiescencia en aquellos negocios habituales y de poca envergadura para la vida; la patria potestad residía exclusivamente en el padre de familia; se les impidió el cargo de tutoras, quedaban postergadas de los consejos de familias y no podían ser nombradas albaceas en testamentos; tampoco donar, ni aceptar ni repudiar donaciones, ni herencias, solicitar partición de bienes, etc; la licencia marital era el único medio.

Ante este escenario normativo, que no deja de ser un reflejo social, Carmen de Burgos creyó en la literatura como motor de cambio. En sus escritos reflejó la necesidad de transformación sin renunciar a unas esencias culturales diferenciadoras entre géneros.

\footnotetext{
${ }^{4}$ MINESSO, Barbara: "Malcasadas vencidas y liberadas. Anhelos de cambio en la narrativa de Carmen de Burgos, 'Colombine”. Cuadernos de Aleph, 3 (2011), p. 181.
} 


\section{Biografía}

Resulta atinado conocer las vivencias de la escritora para comprender sus solicitudes y denuncias. Carmen de Burgos Seguí (1867-1932) nació en Almería y perteneció a una familia acomodada e influyente; su padre, José de Burgos, fue vicecónsul de Portugal en Almería. Contrajo nupcias en 1883 con el periodista almeriense Arturo Álvarez Bustos, alumbrando varios vástagos, de los que le sobrevivió solamente una hija. En 1895 ganó el título de maestra de primera enseñanza en Granada, provincia que por entonces disfrutaba de la influencia de la Institución Libre de Enseñanza ${ }^{5}$ cuyo espíritu de libertad rezumará en sus obras.

Su matrimonio fracasó, abandonó a su marido en 1899. Se marchó con su hija a Madrid, el ambiente provinciano de Almería le asfixiaba. A partir de entonces Carmen se dedicó a la enseñanza y a la poesía. Sus méritos fueron premiados con merecidos galardones entre los que se encuentra la medalla conmemorativa por la Coronación de Alfonso XIII. En 1903 la contrató el periódico Diario Universal. Logró un éxito indiscutible como periodista y escritora, recibiendo homenajes, tanto en Portugal como en Iberoamérica por su labor en defensa de los derechos de las mujeres y su calidad literaria ${ }^{6}$.

La periodista ${ }^{7}$ y escritora, que utilizó el seudónimo de «Colombine», fue una de las precursoras más decididas a favor de la legalización del divorcio. Así lo evidencia la encuesta que planteó en 1904 a los lectores del Diario Universal sobre la conveniencia o no de implantarlo. José Luís Abellán afirma que el debate en el periódico motivó el escándalo y también evidenció que a principios del siglo XX comenzaron a quebrase algunos cánones sociales vigentes desde la Restauración ${ }^{8}$.

Perteneció al Ateneo de Madrid junto a otras intelectuales como Emilia Pardo Bazán y entabló amistad con personajes ilustres de su época, entre ellos Benito Pérez Galdós, Ramón María del Valle Inclán, Juan Ramón Jiménez, Blasco Ibáñez, Mariano Belliure... También mantuvo una relación amorosa con el célebre escritor Ramón Gómez de la Serna, veinte años más joven?

${ }^{5}$ Véase BEMERCKER, W. L.: España entre tradición y modernidad. Politica, economía y sociedad (siglos XIX y XX). Madrid, Siglo XXI, 2009.

"Véase NAVARRETE GALIANO, R.: "Carmen de Burgos en Argentina”, Estudios románicos. Número 27 (2018) p.111-116.

7 Trabajó como maestra y pedagoga, lo cual le permitió realizar numerosos viajes por Europa, también a comienzos del siglo XX colaboró como periodista en el Diario Universal, fue la primera corresponsal de guerra española y fundó y colaboró en diversas asociaciones feministas. En el extranjero también conoció y entabló amistades con Alfredo Naquet, impulsor del divorcio en Francia y con el célebre intelectual Max Nordau.

8 ABELLÁN, J. L.: "Carmen de Burgos y el divorcio en España”. Ciclo de Conferencias sobre Carmen de Burgos, Colombine (1867-1932) en el periodismo y la literatura. Madrid, Universidad Complutense, 2010, p. 24.

${ }^{9}$ Los datos biográficos sobre Carmen de Burgos han sido recogidos de la publicación realizada por NÚÑEZ REY, C.: Carmen de Burgos “Colombine”, en la Edad de Plata de la Literatura Española. Sevilla, Fundación José Manuel Lara (Biografías), 2005. 
Su obra fue copiosa. En sus publicaciones narraba, a veces con escándalo en la opinión pública, las vivencias de sus innumerables viajes por Europa, África y América, describiendo la cultura, el arte y las costumbres, el nivel de desarrollo y las mentalidades de los países que visitó.

Tras la Guerra Civil, al igual que el de otros escritores de ideas avanzadas, su legado fue vetado. Una mujer con ideales tan progresistas y laicos no podía gozar de popularidad en el régimen nacional-católico. Será en 1976 cuando la historiadora Elizabeth Stacevic comience a rescatarla del olvido $^{10}$.

La obra narrativa de De Burgos se compone de treinta cuentos (desde 1900 a 1909) ochenta novelas cortas (1907-1932) y doce novelas largas (1909-1931) ${ }^{11}$. Para muchos filólogos su obra posee mayor interés social o histórico que literario; otros sostienen que sus escritos alcanzaron un nivel muy estimable con calidad suficiente para formar parte de la Edad de Plata de la literatura española ${ }^{12}$.

Nos vamos a centrar en su novela La malcasada. Fragmentaremos las principales ideas que la autora transmite.

\section{La malcasada}

La novela La malcasada se publica en 1923 por la editorial Sempere. La obra, además de aportar caracteres autobiográficos, denuncia la opresión que sufría la mujer de la España del primer cuarto del siglo XX.

La trama describe la relación virulenta entre los esposos Dolores y Antonio. La protagonista llega al matrimonio repleta de ilusión, sin embargo, la ausencia de afinidad emerge con prontitud. Se producen disputas constantes y el marido, que disfruta discutiendo con su esposa, comienza a abusar del alcohol. El maltrato físico pasa de ocasional a cotidiano. Pepe, el tercer personaje típico en De Burgos, aparece como el sueño anhelado y no consumado que salva emocionalmente a la protagonista de la desdicha.

La vida de Dolores deviene insoportable y solicita el divorcio. Los tribunales de justicia desestiman sus pretensiones y perpetúan su suplicio. Finalmente, la protagonista mata a su esposo al intentar violarla.

La novela posee enormes críticas a la sociedad de su época. Destacamos:

-Crítica a la educación femenina

\footnotetext{
${ }^{10}$ STARCEVI, E.: Carmen de Burgos, Defensora de la Mujer. Almería, Editorial Cajal, 1976.

${ }^{11}$ CATRINA IMBODEN, R.: Carmen de Burgos “Colombine” y la novela corta. Berlín, Meter Lang, Bern, 2001.

${ }^{12}$ NUÑEZ REY, C.: op.cit. p.24.
} 
Los primeros mensajes que la autora transmite versan sobre el aislamiento en la infancia y juventud del sexo contrario, sin apenas contactos. La influencia krausista en sus escritos se aprecia con evidencia ${ }^{13}$ :

"Educada en un colegio, casada antes de tener amigas y experiencia, sin más familia que un padre rico, viudo y joven, demasiado ocupado en sus asuntos para dedicarse a ella, Dolores desconocía la vida. No veía, del inmenso panorama desplegado ante sus ojos, más que el espacio que ella iba viviendo, lo que consumía y gastaba en sí misma: su existencia desligada del conjunto general”"14.

El mensaje de inmadurez al contraer nupcias se describe, al igual que la desilusión por el error en la elección. La decisión del matrimonio, sin duda una de las decisiones vitales, debía dejar opción a la enmienda:

"Antonio había sido su primer novio; se casó entusiasmada, soñando con el idilio de la vida provinciana, en una perpetua y mutua adoración. Cuando el mismo día de la boda tomó el tren con su marido para ir a Almería, comenzó su desencanto. No encontró en la brusquedad del deseo de Antonio la dulce ternura y la suave caricia que había esperado"15.

Recordemos que la escritora se casó muy joven y vivió diecisiete años junto a su esposo en Almería hasta su separación. Su relación se volvió insostenible y decidió marcharse a Madrid con la hija común a emprender una nueva vida sin oponerse a nuevas relaciones amorosas. Esta trasgresión, junto a otras, originó comentarios despectivos hacía su honor ${ }^{16}$.

Carmen de Burgos transmitió con nitidez una educación femenina, y especialmente la de clase media, que la abocaba al acatamiento y a la resignación. La infancia de la protagonista lo demuestra: alejada de la sociedad, sin contacto personal con hombres y sin experiencias de convivencia en las escuelas que la conduce al analfabetismo emocional y social. La obediencia y la sumisión al marido se manifiestan sin enmascaramiento ${ }^{17}$. Los moralistas de la época invitaban a ese aislamiento, defendían una educación privada, singularmente la femenina, con el fin de no tener un contacto “demasiado anticipado" con otros niños o con el maestro ${ }^{18}$.

${ }^{13} \mathrm{El}$ análisis que Elvira Ontañón realiza sobre la Institución Libre de Enseñanza, refleja la visión social y académica de Carmen de Burgos. Para Ontañón la ILE era "un grupo humano, abierto, dotado de un talante que era el resultado de unos ideales libremente asumidos, y que vivía un género de vida coherente con ellos". ONTAÑON, Elvira: Un estudio sobre la Institución Libre de Enseñanza y la mujer. Valencia, Colección Letras Humanas, Universidad Politécnica de Valencia, 2003, p. 9.

14 DE BURGOS SEGUI, C.: La malcasada. Valencia, Editorial Sempere, 1923, p. 27.

15 Ibídem.

${ }^{16}$ En su pueblo natal, Rodalquivir, un prostíbulo se nombró con su pseudónimo: "Colombine".

${ }^{17}$ Los manuales docentes femeninos de la época, como Flora y la educación de una niña, instruían en tal sumisión. Véase DE SAN JUAN, P.: Flora o la educación de una niña. Barcelona, Imprenta Elzeviriana y Librería Camí, SA, 1928.

18 RABATÉ, C.: ¿Eva o María? Ser mujer en la época isabelina (1833-1868). Salamanca, Ediciones Universidad de Salamanca, 2007, p.50. 
Correspondía a las madres monopolizar esas enseñanzas que como bien sostiene Margarita Ortega, debían "transmitir y hacer cumplir a sus hijas para que, a su vez, ellas las transmitieran a sus descendientes femeninas" $" 19$.

Sin duda la formación académica del género femenino centró una de las reivindicaciones del feminismo original. Concepción Arenal ${ }^{20}$ y Gimeno de Flaquer ${ }^{21}$, entre otras, insistieron en la necesidad de transformación del sistema educativo femenino, para ellas, el sistema las abocaba a la estulticia. La autora era consciente, sin duda, de las limitaciones que la falta de formación acarreaba en la libertad de las mujeres, impidiendo cualquier emancipación posible ${ }^{22}$.

Sin embargo, De Burgos no se centra en la formación, sino en la educación diferenciadora entre géneros dentro del hogar, germen de la superioridad masculina.

\section{- Crítica al derecho de posesión masculina}

El desapego entre los cónyuges a lo largo de la novela se incrementa, Dolores no sólo no ama a su esposo, comienza a aborrecerlo, y las pautas sociales niegan la libertad e imposibilitan la ruptura:

"No sufría ya por el amor de su marido, sino por su amor propio de mujer, por la pérdida de las ilusiones pasadas y por el miedo al porvenir... Dolores, frente a todo aquello, pensaba si no sería mejor morir que volver a tomar su papel entre aquellas gentes, para continuar siendo la esposa de un hombre que se le había hecho aborrecible. Deseaba ardientemente que ya no la amase, que no volviera a desear ejercer sus derechos de marido"23.

La protagonista suplica a su esposo que no mantenga relaciones sexuales con ella, que viviría con él, pero que no le hiciera pasar por el trance amargo de poseerla carnalmente. Este planteamiento ya lo expuso el socialdemócrata August Bebel. El pensador se sorprendía del rigor católico que obligaba a los casados a permanecer unidos en un vínculo, que en esencia, no solamente podía no existir, sino que incluso obligaba a la unión carnal en casos de aborrecimiento entre los cónyuges. Para el socialista mantener el lazo entre personas que no lo deseaban e impedir la libertad de ruptura desembocaba en la esclavitud femenina. Planteaba el pensador alemán que la mujer que despreciaba a su esposo y se veía obligada a mantener relaciones sexuales con él, no la degradaba más incluso que la prostitución, pues su sometimiento no tenía ni límite en el tiempo ni posibilidad de oposición:

19 ORTEGA LÓPEZ, Margarita: "La defensa de las mujeres en la sociedad del Antiguo Régimen". En FOLGUERA, Pilar (Ed): El feminismo en España: dos siglos de historia. Madrid, Pablo Iglesias, 2007, p. 13.

20 ARENAL, Concepción: La mujer del porvenir. Madrid, Bibliotecas de Escritoras, Instituto de la Mujer. 1993.

21 GIMENO DE FLAQUER, Concepción: Mujeres vidas paralelas. Madrid, Tipografía de Alfredo Alfonso, 1893.

22 Véase Romero Moreno, Yasmine: “Obsesiones feministas de Doña Carmen de Burgos Seguir, una escritora del siglo de plata español”, Cuadernos del Ateneo. Número 32 (2014), p.20.

23 DE BURGOS SEGUI, C.: La malcasada... op. cit., pp. 90-91. 
"Así, pues, hay personas que de por vida permanecen encadenas unas a otras en contra de su voluntad. Una parte se convierte en esclava de la otra y se ve obligada a someterse a los abrazos más íntimos de la otra parte por deber conyugal, cosa que tal vez le repugne más que los insultos y los malos tratos (...) ¿No es un matrimonio así peor que la prostitución?”24.

\section{- Crítica al depósito judicial}

La marginación, no sólo social, también legal, de la separada aparece. Ésta era despreciada socialmente y más si la ruptura la había planteado ella. Separación equivalía a postergación. En el siguiente fragmento entre Dolores y Pepe, su amante y abogado, se clarifica la situación:

“-Hágame usted parecer a mí culpable.

-¡Está usted loca! Se ve que no conoce la ley. Se la recluiría en una prisión o en un manicomio.

-Pero me vería libre de ese hombre, que ha pisoteado lo más noble que había en mi alma, exclamó ella con arranque.

El joven pareció conmoverse, pero, como el que cumple un penoso deber, prosiguió:

-¿Cree usted que se vería libre?

-iNaturalmente!

-No. Estaría usted toda la vida sujeta a su vigilancia. Le nombraría a usted un depositario, una especie de tutor despótico... Estaría usted siempre sujeta a él.

-Pero el día en que se falle...

-No se falla nada nunca en este género de asuntos. Parece que la ley la han hecho solterones que querían fastidiar a los que se casan.

-¿Entonces?

-La ley está de parte de los hombres... y hasta si tuviera usted hijos, él, con su mala conducta y todo, le arrebataría a usted los mayores de tres años" 25 .

La novela expresa la realidad jurídica de la separación. El control de la mujer separada por parte del varón se constata. La sociedad patriarcal no podía consentir la liberación de la mujer, y por ello, le endosaba un tutor depositario para controlarla ${ }^{26}$. El depósito judicial consistía en encomendar a un tercero, generalmente pariente o persona de confianza, la custodia de la mujer separada, con el fin, al menos formalmente, de que tuviera las necesidades básicas cubiertas, nos referimos a techo, lecho, alimentos y vestimenta. Se buscaba, en definitiva, una morada estable para la esposa separada. La regulación de esta institución jurídica merece atención, su análisis nos describe con nitidez el raciocinio que a la mujer se le estimaba. En primer lugar, el Código civil, en su artículo 68 regulaba la institución derivando su aplicación a la Ley de Enjuiciamiento civil (LEC), aprobada en 1881.

24 BEBEL, August: La mujer y el socialismo. Madrid, Arkal 74, 1977, p. 190.

${ }^{25}$ DE BURGOS SEGUI, C.: La malcasada ... op. cit., p. 144.

${ }^{26}$ Artículo 68 del Código civil de 1889 y artículo 1897 de la Ley de Enjuiciamiento civil de 1881. 
En su artículo 1880 la LEC estipulaba:

"Art. 1.880. Podrá decretarse el depósito:

$1 .^{\circ}$ Dé mujer casada que se proponga intentar, ó haya intentado demanda de divorcio, ó querella de amancebamiento contra su marido, ó la acción de nulidad del matrimonio.

2. ${ }^{\circ}$ Dé mujer casada contra la cual haya intentado su marido demanda de divorcio ó querella de adulterio ó la acción de nulidad del matrimonio.

3. ${ }^{\circ}$ La mujer soltera que, habiendo cumplido 20 años, trate de contraer matrimonio contra el consejo de sus padres o abuelos".

Para Leire Imaz la regulación del depósito respondía a la consideración de que la vivienda conyugal era "la casa del hombre". Ante tal situación se hacía necesario "depositar" a la mujer en la casa de algún familiar o en un convento ${ }^{27}$.

Además de ese argumento patrimonial, el depósito responde a un espíritu de sometimiento-protección. Sometimiento, y esta es la perspectiva que la autora destaca, porque le impide su libre desenvolvimiento y la obliga a seguir las directrices de un responsable. Protector porque se consideraba que la mujer no poseía raciocinio ni fortaleza física suficiente, por ello, requiere la vigilancia-protección de un varón nombrado con unos requisitos determinados.

La ley regulaba también la posibilidad de acogerse a esta institución a las mujeres solteras, mayores de 20 años, que aspirasen a contraer nupcias sin el consentimiento de sus padres e incluso abuelos y a los hijos incapacitados, maltratados o desamparados. La casi inexistente capacidad de decidir de la mujer se expresa, de nuevo en el artículo 1882 de la LEC, la norma otorgaba la decisión de elección del depositario al esposo junto al juez, y en caso de desavenencia al juez exclusivamente. También sería éste el que decidiese el depósito en caso de incomparecencia del marido. De la lectura de estos artículos se desprende la casi ausencia de decisión femenina ${ }^{28}$ :

27 IMAZ SUBIRÁ, Leire: "Superación de la incapacidad de la mujer casada para gestionar su propio patrimonio". Mujeres y Derecho, pasado y presente. I Congreso multidisciplinar de Centro-Sección Birkeaia de la Facultad de Derecho. p.77.

28 Art.1.882 de la LEC: Presentada la solicitud, se trasladará el Juez, acompañado del actuario á la casa del marido; y sin que este se halle presente, hará comparecer á la mujer para que manifieste se ratifica o no en el escrito en el que se haya pedido el depósito. Si la mujer no se encontrare en la casa del marido se practicará la diligencia expresada, y las demás a que se refieren los artículos siguientes, en aquella en que se encontrare, citando previamente al marido con señalamiento de día y hora, bajo apercibimiento de que sin más citación se realizarán dichas diligencias aunque no concurra. No estando presente él marido, decidirá el Juez lo que corresponda.

Art. 1899. Constando la admisión de la demanda ó de la querella, el Juez se trasladará á la casa del marido; procurará que se ponga de acuerdo con la mujer sobre la persona en quien hubiere de constituirse el depósito; y si no convinieren, nombrará el Juez la que, el marido haya designado, si nó hubiere razón fundada que lo impida. Habiéndola, elegirá a quien estime más á propósito. Ley de Enjuiciamiento civil de 1881. 
El depósito fue derogado en la modificación del Código civil de 24 de abril de 1958. En dicha reforma se aspiró a no diferenciar, al menos formalmente, entre géneros respecto al dominio de la vivienda conyugal. Así, en las medidas provisionales de la separación se estipuló: "determinar cuál de los cónyuges ha de continuar en el uso de la vivienda común, teniendo en cuenta, ante todo, el interés familiar más urgentemente necesitado de protección, así como las ropas, objetivos y muebles que podrá llevar consigo el cónyuge que haya de salir de aquella" ${ }^{29}$. El cambio, al menos, no diferenció formalmente entre cónyuges a la hora de ocupar la vivienda.

María José Muñoz García sostiene que la condición jurídica de la mujer casada coaligaba dos causas que limitaron su capacidad de obrar: el sexo y el matrimonio, las cuales unidas limitaban poderosamente sus posibilidades de actuación ${ }^{30}$. El civilista José Luís Lacruz Berdejo afirmaría años después que la posición legal de la mujer casada en España era la más estricta y sumisa de Europa ${ }^{31}$.

Además, el artículo 57, como se dijo con anterioridad, establecía que la esposa debía obedecer al marido y éste protegerla. La idea que subyace y justifica la norma es que ella es débil, él fuerte, debiendo ampararla por su superior fortaleza física e intelectual.

Para Leire Imaz el discurso de la época las situaba en una inferioridad física e intelectual justificada por su naturaleza más "débil". La resignación y la sumisión femenina eran "normas de vida" y "virtud" debiendo la mujer adecuarse a la función social que se le supone. Para la mencionada el discurso de inferioridad no era exclusivo ni de conservadores ni de católicos, los laicos también emitían un discurso análogo sobre la mujer, consideraba su adoctrinamiento ineludible para frenar sus pasiones ${ }^{32}$.

- Defensa del divorcio

La crítica al atraso social y jurídico de España respecto a numerosos países europeos se percibe en la obra de la escritora ${ }^{33}$. En este punto influyeron en la autora dos elementos importantes, de una parte, el regeneracionismo, que miraba a Europa para devolver a España la vitalidad perdida durante siglos; y de otra, sus numerosos periplos por Europa, donde in situ comprueba los enriquecedores beneficios que el divorcio aporta a las sociedades.

${ }^{29}$ Boletin Oficial del Estado. 25 de abril 1958.

${ }^{30}$ MUÑOZ GARCÍA, María José: Las limitaciones a la capacidad de obrar de la mujer casada. 1505-1975. Madrid, UNEX, 1991, p.18.

${ }^{31}$ LACRUZ BERDEJO, José Luís: El nuevo derecho civil de la mujer casada. Madrid, Cuadernos civitas, 1977, p. 7.

32 IMAZ ZUBIAUR, L: op. cit., 71.

33 Véase HILARIO AYUSO, M. y SANZ MARCO, B.: La Ley del Divorcio. Textos y comentarios. Madrid, Librería General de Victoriano Suárez, 1932. 
El divorcio se generalizó en Europa en el último tercio del siglo XIX, salvo los países de mayoría católica. Alemania lo permitió en la mayoría de sus estados de mayoría protestante; Inglaterra lo aprobó en 1857; Francia en 1884 con la Ley Naquet; sólo Italia, Polonia, Irlanda y España, excepto con la breve vigencia de la Ley de 1932, permanecieron sin una ley de divorcio hasta 1981.

En un fragmento se detalla con brillantez el pensamiento progresista de la autora sobre el divorcio. En una conversación entre varios personajes ${ }^{34}$ que representan mentalidades antagónicas, uno de ellos lo defiende con un criterio racional y antidogmático; otro lo rechaza por inmoral:

“-Usted se cree -exclamaba el italiano- que con la ley de divorcio iban a tirar del marido por un lado y de la mujer por otro y separarlos a la fuerza; pero no señor, el divorcio es un remedio para los que sufren, como la quinina para las fiebres; quien no lo necesita no lo toma. Los biencasados no se separan por eso, y unos y otros cuidarán más de hacerse la vida agradable y no los oiremos decir a cada paso: "Yo ya no tengo que agradar".

-iPalabras! ¡Palabras! -decía el gentilhombre. No valen esas comparaciones de usted. La quinina es amarga y el vicio es dulce. Pobre sociedad si el matrimonio no fuera más que un contrato como quieren los impíos. Se disolvería la familia. ¡Más vale que sufran unas cuantas, que no la inmoralidad de todas!

-...Es inhumano condenar a dos personas a vivir juntas, aunque no hubiera motivo ninguno para su repugnancia. Eso de no haber más medio de liberación que la muerte, hace cometer el pecado de desear que mueran muchos cónyuges.

-Exagera usted." 35 .

El mensaje tácito enviado por la Iglesia y los grupos conservadores para apaciguar las ansias rupturistas consistía en defender la negación del "yo" en favor de un ente superior "la familia". Sin embargo, el sacrificio correspondía a la mujer y la autora revela su inconformismo durante el desarrollo de la novela.

- Críticas a las solteras

Otra de las invectivas se centra en el sistema patriarcal dominante que sojuzga a la casada y desprecia a la soltera que vivía sin la protección y amparo del hombre. Las críticas a la solterona se alimentan por las propias mujeres, sin embargo, y como prueba de diferenciación, el solterón no es contemplado con ese matiz de fracaso: "Cuenta las historias de las solteronas y de cómo buscar novio para casarse por lo malo que resulta ser solterona, no en cambio para el hombre"36.

La temática de la mujer soltera que ansiaba un marido que le remediara la vida también aparece

\footnotetext{
${ }^{34}$ Carmen de Burgos poseía una magnifica habilidad para describir personajes de la época. STARCEVI, E.: Carmen de Burgos, Defensora de la Mujer. Almería, Editorial Cajal, 1976, p. 55.

35 DE BURGOS SEGUI, C.: La malcasada... op. cit., p. 29.

36 Ibidem, p. 87.
} 
en otras obras literarias de la época ${ }^{37}$. La mujer de clase media había sido aleccionada con el fin de encontrar su estabilidad económica y social en un esposo, lo que en definitiva la situaba en una continua minoría de edad, de dependencia, de sumisión cuando no de indiferencia por parte del cabeza de familia: “-Sí -dijo Pepe riendo-; pero véngales usted con esas teorías a las que, sin ser emancipadas, han pillado un hombre que las mantenga, y a todas esas niñas que andan a caza de maridos para hacerse un seguro de vida..."38.

El matrimonio para la mujer resultaba primordial, para Colette Rábate era la única forma de existir socialmente ${ }^{39}$.

\section{- Descripción del peso patriarcal en la sociedad}

La relación conyugal, como ya comentamos anteriormente, se deteriora de tal forma que Dolores pide el divorcio. El marido se sorprende ante la solicitud de separación de la mujer. No concibe los motivos, él siempre se comportó con ella de acuerdo con los cánones exigibles a un buen marido, así aparece descrito en una conversación entre Alfredo y un personaje secundario:

“-¿Pero en qué se funda esa mala mujer para quejarse de mí?

-En sevicia.

-¿Qué es eso?

-Malos tratos.

- ¿Y será capaz? ¡Malos tratos yo! ¡Que me he pasado de bueno! ¿Cuándo le ha faltado a mi lado de comer y de vestir y todo lo que ha querido?

-Las mujeres son así.

-¡Mala ralea! '¡Hay que tratarlas a puntapiés y no como yo lo he hecho! Pero te juro que me las ha de pagar" 40 .

La respuesta a la solicitud de independencia femenina, en muchos casos, consistió en el maltrato físico. Adriana Cases Sola afirma: “...la no aceptación por parte de algunos hombres de los avances de las mujeres y sus deseos de independencia daba lugar a situaciones de violencia en las que las mujeres eran las víctimas"

Catherine Jagoe destaca que el valor del sacrificio de la mujer aparecía sólidamente enraizado en la mentalidad femenina que lo magnificaba como un camino para encontrar la

37 Emilia Pardo Bazán y Margarita Nelken, entre otras, también censuraran esta actitud generalizada en la mujer, especialmente de clase media. Véase PARDO BAZÁN, Emilia: Doña Milagros y Memorias de un solterón. Madrid, Fundación José Antonio de Castro, 1990 y NELKEN, Margarita: La Trampa del Arenal. Madrid, Castalia, 2000 .

38 DE BURGOS SEGUI, C.: La malcasada ... op. cit., p. 146.

39 RABATÉ, Colette: ¿Eva o María?. Ser mujer en la época isabelina (1833-1868). Salamanca, Ediciones Universidad de Salamanca, 2007, p.57.

${ }^{40}$ DE BURGOS SEGUI, C.: La malcasada, op. .cit., pp. 174-175.

${ }^{41}$ CASES SOLA, Adriana: "La violencia de género durante la Segunda República", Hispania Nova. Revista de Historia Contemporánea. Número 11 (2013). 
dicha: “...únicamente dentro del hogar y cumpliendo ese papel de auto-inmolación es la manera en que la mujer se encuentra dichosa"42.

El asentamiento patriarcal se refleja en la familia de Dolores. La aceptación de la indisolubilidad del matrimonio y del deber de sacrificio de la esposa estaba tan asentado que incluso los progenitores no apoyan los anhelos de sus hijas cuando el desafecto y la desdicha se instalan en la relación matrimonial. La protagonista ruega el auxilio de su padre mostrándole su situación, sin embargo, él, lejos de rebelarse, invita a su hija al acatamiento y al conformismo: al contraer matrimonio había dado un paso irreversible en la vida y tenía que asumirlo. En este fragmento se vislumbra el fondo andrógeno que obvia el sentimiento de la otra parte e impone el inmovilismo. Al fin y al cabo, su padre se había comportado de igual modo con su esposa:

"Yo nada puedo hacer, le decía. Le he escrito a tu marido aconsejándole y me asegura que te quiere y procura hacerte dichosa. Tú lo has elegido. Ya sabes que siempre te he dicho que con la cuchara que eligieras comerías. Antes de casarte ya sabías cómo era. Antonio no es malo....

¿Cómo no había de ser ese el criterio de su padre? ¡Hombre también!

El recuerdo que le quedaba de su madre era el de una mujer martirizada. Su padre, con fama de buen marido, había tenido devaneos, que ella sufrió como cosa obligada. Se plegó en todo a la voluntad del esposo. Jamás pudo descotarse, ni fue dueña de vestirse a su gusto, ni de ir a ninguna parte"43.

Descuella un fragmento en el que se descubre la desigualdad entre géneros, Antonio no considera a su esposa una igual, él está por encima social y legalmente, no tiene por qué respetar a su esposa:

"-No, no te tengo rencor..., te lo perdono todo... seré tu esclava para todo lo que quieras... yo te cuidaré... te guisaré... velaré por la casa... No te diré jamás nada que te moleste... Pero vete, Antonio, vete...

-¡Tiene gracia! ¿Que me perdonas? ¿Que me vaya? ¡Sí que tiene gracia! ¿Te has llegado a creer que yo no puedo buscar a mi mujer cuando quiera y me dé la gana?44.

-¿Se puede saber dónde ha estado la señora esta mañana? — le preguntó sin tomarse el trabajo de saludarla.

Ella se sentía ya fuerte.

-¿Te pido yo cuentas a ti?

El respondió con otra pregunta:

-¿Pero es que te has llegado a creer que eres igual que yo?"45.

- Crítica a la actitud conformista de la mujer

\footnotetext{
42 JAGOE, C.: "La misión de la mujer". En JAGOE, C.; BLANCO A. y ENRIQUEZ DE SALAMANCA, C: La mujer en los discursos de género. Textos y comentarios del siglo XIX. Barcelona, Icaria Antrazyt, Mujeres, voces y propuestas, 1998, p. 40.

${ }^{43}$ DE BURGOS SEGUI, C.: La malcasada ... op. cit., p. 111.

${ }^{44}$ Ibidem, p. 266.

45 Ibidem, p. 165.
} 
De Burgos, con un espíritu vitalista enemigo de la apatía y del statu quo, no solamente censura el sistema patriarcal, también la indolencia de la mujer casada:

“...jamás podría acostumbrarse al espíritu del país y ser, como las otras mujeres, sometidas y pasivas, que veían deslizarse la vida sin hacer nada, casi sin pensar en nada, esperando que el esposo y señor, que aún conservaba algo del dominio árabe, fijase la atención en ellas y las emplease en su servicio" 46 .

"La apatía de las esposas en sus relaciones conyugales la exacerba, no entiende el conformismo y resignación de las mujeres mal casadas: Aparecían las quejas, el descontento: eran en su mayoría malcasadas, resignadas, como seres en los que no se había definido la personalidad; pero que sufrían con paciencia bovina la carga de una vida vulgar, sin ideales, sin satisfacción, sin aspiraciones" ${ }^{47}$.

El mensaje reitera las críticas del feminismo primigenio. El análisis de las obras de Concepción Arenal, Emilia Pardo Bazán, Concepción Gimeno de Flaquer, entre otras, descubre esta situación de abulia tan generalizada y censurada en las pensadoras feministas. Otro de los tópicos sociales denunciados se centró en la crítica a la desidia femenina tras lograr el enlace matrimonial. De Burgos censura la actitud de buena parte de las mujeres de su época al asegurar que la casada, una vez contraído el vínculo, se desliza hacia la apatía física e intelectual al considerar que todo se resolvía con las nupcias:

“...Poco a poco se iba abandonando en sus cuidados personales y en su atavío. No cuidaba de la casa, no leía, no hacía ninguna labor. Su espíritu se dormía para caer en un estado de inercia, de indiferencia, que no estaba lejos de la idiotez. Iba siendo lo que allí se entendía que debía ser una mujer casada"48.

El rol masculino se aprecia con claridad, el hombre podía hacer lo que deseara siempre y cuando sostuviera la economía familiar, ya que con aportar estabilidad económica cumplía su función. La deshonra grave para el hombre venía del incumplimiento de esta obligación:

"Lo más raro era que toda la opinión se volvía contra Dolores (...) porque después de todo no es ningún criminal, ni abre ningún libro nuevo. Hace lo que todos los hombres... Una mujer decente no puede ser así -decían-. Los hombres son hombres; hay que hacer un poco la vista gorda y dejarlos que corran, con tal de que no falte lo necesario en la casa." ${ }^{\prime 4}$.

- La honra

46 Ibidem, p. 28.

${ }^{47}$ Ibidem, p. 87.

48 Ibidem, p. 262.

49 Ibidem, pp. 107-108. 
La propia concepción del honor masculino abunda en la misma idea de superioridad y desproporción entre géneros al ligarse su lesión a la infidelidad de la esposa frente a la situación inversa, la del adulterio masculino, que era una práctica relativamente frecuente y socialmente tolerada. El tema aparece en la obra a propósito de las advertencias de Antonio a Dolores, a la que no le va a consentir que falte a su honor: “... Aunque no conozco bien tu vida de soltera, me figuro lo que habrás sido... pero si te crees que yo voy a ser un... consentidor, como tu padre, te equivocas. Estoy dispuesto a rajarte de arriba a abajo, a abrirte en canal" ${ }^{\prime 50}$.

La salvaguarda de la castidad de la familia perteneció exclusivamente a la mujer. Manuel Bustos sostiene que el espíritu de recato irradió Europa desde la Edad Media hasta la Edad Contemporánea: El valor moral poseía honda relevancia, no solamente por la posible censura social de la que la quebrantara, sino también para sus hijos y descendientes ${ }^{51}$.

"El qué dirán" sustenta la inacción de la mujer. Era deseable sufrir infidelidades o malos tratos antes que hacer pública una situación tan infamante. De esta forma consolidaban la situación ignominiosa:

"Todas aquellas señoras eran, a pesar de eso, respetadas y consideradas, porque tenían la hipocresía necesaria para no romper con los convencionalismos de la sociedad. Se toleraban los engaños con tal de que se guardasen las apariencias" 52 .

\section{- El valor sentimental en el matrimonio}

Los motivos sentimentales comenzaron a ser fundamentales en la reivindicación del divorcio. La autora suscita la cuestión de forma insistente, para ella, no sentir afecto por el otro cónyuge es motivo suficiente para romper el vínculo, de esta forma se alineaba con un nutrido elenco de intelectuales de principios del siglo XX para los que el amor era la clave del matrimonio, el objeto último de la institución. La escritora sueca Ellen Kay defendió el sentimiento como único motivo que merecía la pena conservar, desaparecido éste, no tenía sentido mantener esa unión. En su libro Amor y matrimonio reclamaba la imposibilidad de pedir responsabilidad ante promesas amorosas incumplidas:

“...cuando el amor se extingue, el matrimonio carece de razón de ser y debe apelársela derecho para disolver la unión. No importa, que entre los esposos hayan mediado promesas de eterna felicidad, esas promesas no son válidas, porque nadie es dueño de hacer inmutables sus sentimientos" 53 .

50 Ibidem, p. 113.

${ }^{51}$ BUSTOS RODRÍGUEZ, Manuel: Europa, del viejo al nuevo orden. Del siglo XV al XIX. Madrid, Silex, 1996, p. 90.

52 DE BURGOS SEGUI, C.: La malcasada ... op. cit., p. 158.

${ }^{53}$ Citado por DELGADO IRIBARREN, Francisco: El divorcio. ley 2 de marzo de 1932. Madrid, Revista de Derecho Privado, 1932, p. 68. 
Los juristas, sin embargo, no compartían este parecer. Para ellos, el amor y la libertad ocupaban un papel secundario en el matrimonio. Así se expresa el reconocido civilista Castán Tobeñas:

"La libertad posee un papel secundario en las relaciones familiares, pues está subordinada al derecho por existir determinados fines y necesidades naturales, una de ellas es la institución familiar, por imperativo natural" 54 .

"La teoría de la libertad del amor descansa en un doble error desde el punto de vista filosófico: que el fin del matrimonio y de la vida es la felicidad individual; otra de orden antropológico: la de que el hombre es naturalmente bueno y sabe hacer perfecto uso de la libertad, todos síntomas fruto del amoralismo contemporáneo de ideas utilitarias, del eudemonismo (felicidad) egoísmo, placer hedonismo, es lo mismo con distintos nombres pero es en síntesis lo contrario al deber y a la virtud" ${ }^{5}$.

Entendía que las mayores perjudicadas por esta posibilidad eran ellas, debido a su psicología y somatología ${ }^{56}$. Para el civilista el matrimonio indisoluble había sido un logro histórico para la mujer, y a sensu contrario el divorcio las perjudicaba.

Habrá que esperar hasta 1981 para que se produzca en nuestro ordenamiento jurídico, una transformación profunda en este tema y en todo el Derecho matrimonial. En la Ley del divorcio de ese año la afecttio maritales ${ }^{57}$ fundamentará el vínculo conyugal, sin embargo, el legislador no recogió expresamente esta falta como motivo de separación o divorcio, aunque las causas para decretarlos lo evidenciaban. Con esta reforma desaparece el carácter sancionador del divorcio que se sustituye por el corrector "para la recuperación de la paz jurídica de los matrimonios y familias rotas" ${ }^{\prime 58}$.

- Critica a la regulación legal de la crisis matrimonial

En un fragmento de la obra que glosamos, algo extenso pero muy elocuente, se describe con claridad la angustia de las mujeres casadas que ansiaban romper su vínculo. En él critica a la religión que impide la libertad afectiva, singularmente al tribunal eclesiástico de la Rota, y finalmente se reprende la colaboración femenina en el statu quo. La malcasada no albergaba razones para el optimismo:

\footnotetext{
${ }^{54}$ CASTÁN TOBEÑAS, José.: La crisis del matrimonio. (Ideas y hechos). Madrid, Hijos de Reus, 1914, pp. 154155.

55 Ibidem, p. 178.

${ }^{56}$ Ciencia que estudia las respuestas emocionales.

${ }^{57}$ En realidad esta motivación no podía ser alegada debido a su subjetividad. La doctrina y la jurisprudencia ideó el concepto de afecctio maritalis que venía a describir el deseo de hacer vida en común entre cónyuges.

58 PEREZ MARTÍN, Antonio Javier: Derecho De familia. El procedimiento contencioso de separación y divorcio. comentarios, texto legal, casos prácticos, jurisprudencia y formularios. Valladolid, Editorial Lex nova, 1997, p. 161.
} 
"La separación, que aquí llamamos divorcio, no se llega a fallar casi nunca....

-¿Pero cuando se falle el divorcio yo dejaré de ser ya la esposa de...? marido...

-No, no señora. El vínculo subsiste siempre. No puede usted dejar de ser la esposa... de... su

-Pero es cruel no poder romper esa cadena que amarra a dos personas que no se aman.

-La cadena es sólo para la mujer, amiga mía. Las costumbres tienen una fuerza sobre el espíritu, superior a la de las leyes....

-Pero una vez separados...

-Él conserva siempre, mientras el divorcio no se falle, y no se falla nunca, una autoridad sobre usted.

-¡Ay! Amigo mío. Crea usted que con eso me basta. No quiero más felicidad que el verme lejos de ese hombre. Tranquila. Yo he llegado a la conclusión de que lo que más se parece a la felicidad es la tranquilidad.

...Pedir el divorcio se considera como una ofensa a la religión, que ha hecho del contrato matrimonial un sacramento indisoluble. La Rota no llega nunca a fallar un divorcio y la Curia pone todos los inconvenientes para admitir las demandas.

-Pero cuando está claro...

-Nada, ...cuando una mujer - decía- es joven y bonita y tiene la desgracia de ser una malcasada, sólo se le ofrecen tres caminos: el primero, el de resignarse a sufrirlo todo, a matar su dignidad para acomodarse a él o morirse de asco y de tristeza; el segundo, que toman la mayoría, es el del engaño y la hipocresía; el tercero, que algunos espíritus nobles arrostran con valentía, es el de la separación, pero sólo logran vivir una vida truncada, descentrada, mutilada"59.

La esposa que solicitaba la separación y no se fallaba se veía obligada a vivir con el esposo. El artículo 58 del Código civil disponía el deber de la mujer a fijar su domicilio según fuera el de su marido. Si la esposa se resistía, las fuerzas del orden la obligarían a trasladarse al domicilio junto a él. La Sentencia del Tribunal Supremo de 25 de octubre de 1927 se expresaba sin ambigüedades en este sentido al exigir a las fuerzas de seguridad el traslado de la mujer que se negase a compartir residencia con el marido ${ }^{60}$.

El desenlace de la novela concluye en tragedia. Tras la demanda de separación presentada por Dolores, los tribunales no conceden la separación solicitada por entender que faltan pruebas. El simple hecho de no amar a su esposo no concede tal fallo.

Antonio, tras ejercer sus derechos conyugales, fuerza carnalmente a Dolores que clava unas tijeras en su rostro para librarse de la violación. La obra finaliza con esa muerte. La mayoría de las novelas de Carmen de Burgos finalizan con tragedias. La opresión social y legal asfixia hasta que convertían la vida en aborrecible. Perpetuar la indisolubilidad del vínculo conyugal a toda costa y someter a la mujer casada, en contra de su voluntad podía abocar a abusos e iniquidades no siempre

${ }^{59}$ DE BURGOS SEGUI, C.: La malcasada... op. cit., p. 244.

${ }^{60}$ Sentencia del Tribunal Supremo de 25 de octubre de 1927. Revista General de Legislación y Jurisprudencia. Tomo 177. octubre 1927. Madrid, Editorial Reus, p. 590. 
soportables. Los motivos para el homicidio, presagia la autora, no serían aceptados ni por los juzgadores ni por la sociedad:

"La habían obligado al crimen, negándole todo medio de separarse de aquel hombre. Pero tuvo la rápida intuición de que iban a venir a prenderla...La cárcel se le presentaba con todo su horror y toda su promiscuidad. Se vería vilipendiada, despreciada de todos. Nadie sería capaz de comprender el crimen pasional en una mujer. Nadie se daría cuenta jamás de que la mujer casada pudiese llegar al crimen para defender su castidad, el derecho a la posesión de sí misma, frente a su marido"61.

\section{Conclusiones}

Para Carmen de Burgos la aprobación del divorcio vincular resultaba ineludible y solicitó su aprobación por los medios a su alcance, entre ellos la literatura. Expuso en sus obras la necesidad de legislarlo para mitigar la infelicidad de los matrimonios mal avenidos y aliviar, la opresión femenina y la abusiva regulación y aplicación del Derecho de Familia. En su pensamiento, y reflejó de él su literatura, emergen los ideales de la Institución Libre de Enseñanza, vislumbrando el sometimiento femenino asentado en raíces patriarcales y mentalidades atávicas amparadas por los poderes públicos y la sociedad. Las críticas a la Iglesia aparecen descafeinadas, consciente la autora de la afinidad del mundo femenino a la institución.

Sus críticas a las normas de Derecho matrimonial, a la permisividad ante los malos tratos, a la figura del depósito judicial y a la administración de los bienes exclusiva del esposo, plenamente justificado por la sociedad que presuponía la minoría de edad intelectual de la mujer, avalan la necesidad inaplazable de transformación.

También se detalla y denuncia una visión social de la familia en la que la mancha en la honra condena a las personas al abismo de forma radicalmente dispar dependiendo del género. La mujer no solamente "mancha" la reputación propia, también la de sus descendientes. Sin embargo, la infidelidad masculina se tolera, e incluso se ensalza por su muestra de virilidad.

La marginación social y jurídica que sufría la esposa y lo dañino e irracional del matrimonio indisoluble se denuncia con insistencia. El divorcio se presenta como ineludible. La autora, como acertadamente señala Minesso Barbara, conoce bien la condición legal de la mujer, convierte a ésta en protagonista de su mundo narrativo, y con todos los recursos a su alcance propone cambios y mejoras $^{62}$.

${ }^{61}$ DE BURGOS SEGUI, C.: La malcasada... op. cit., p. 271.

${ }^{62}$ MINESSO, Bárbara: op.cit., p. 181. 
Su literatura planteó constantemente de superar la educación femenina imperante con el ánimo de transformarla. En este campo, al igual que numerosos intelectuales y literatos, De Burgos advirtió lo defectuoso del sistema que abocaba a la mujer al sometimiento, impidiendo o dificultando no sólo la implantación del divorcio también las libertades esenciales. Manifestó la necesidad de evolucionar el sistema educativo y las mentalidades para equilibrar los sexos y mejorar los matrimonios sin renunciar, indudablemente, al divorcio, institución que resolvía los problemas insalvables de los matrimonios mal avenidos. 